\title{
Situational Approach to Suicide Prevention Among Australian Males: The Role of Unemployment
}

\author{
Shravankumar Guntuku \\ Project Officer, Men's Health Information and Resource Center, Western Sydney University \\ E-mail: s.guntuku@westernsydney.edu.au
}

\begin{abstract}
Dr Neil Hall
Director of Academic Program (Social Work \& Community Welfare), Western Sydney

University

E-mail: n.hall@westernsydney.edu.au
\end{abstract}

Anthony Smith

Australian Institute of Male Health and Studies (AIMHS)

E-mail: anthonymsmith12@gmail.com

Received: Jan. 2, 2021 Accepted: Jan. 26, $2021 \quad$ Published: Feb. 1, 2021

doi:10.5296/ijssr.v9i1.18168 URL: http://dx.doi.org/10.5296/ijssr.v9i1.18168

\begin{abstract}
This article contends that the prevention of suicide, particularly in Australia, needs to be re-imagined, by expanding a medical/crisis response to take into account social factors that contribute to the incidence of suicide and suicidal ideation. The particular area of unemployment/underemployment provides one such example of the social determinants of suicide, and argues that the nuances of gender and Aboriginality need also to be accounted for in research and program delivery. This analysis has been dubbed the 'Situational Approach to Suicide Prevention'.
\end{abstract}

Keywords: suicide, unemployment, Australia 
"We need to actively seek to understand and reduce the factors that contribute to despair and suicidal thoughts. This means looking towards the social determinants of suicide, and effective policy shifts as well as interventions that can reduce their impacts".

(Christine Morgan, National Suicide Prevention Advisor to the Prime Minister, 2019)

\section{Introduction}

Despite enormous increases in funding and program activity, suicide deaths have continued to increase over the last 15 or more years in Australia (Bastiampillai et al., 2020) This pattern is similar in a number of similar Western Countries, but currently in Australia, according to the Australian Bureau of Statistics (ABS, 2017), suicide is one of the leading causes of deaths in 2018 amounting to more than 3046 people — or 8.3 deaths each day — which is twice the rate of deaths by motor vehicle accidents, and far higher than homicide deaths at 375 .

Ritchie et al. (2020) estimate that, globally, suicide rates in men are just over twice as high as for women. Australian males are at even higher risk. It is commonly acknowledged that suicide rates are under-reported by at least $20-30 \%$ in Australia, however the ABS (2019) reported that in 2018, 2320 suicides were males and 726 were female. Further, Aboriginal and Torres Strait Islander men and boys aged between 15 to 25 are at higher risk among Australians, as in 2017 alone suicides among Aboriginal and Torres Strait Islanders was four times more than for non-aboriginal people. Haw et al. (2020) show that recent developments in suicide prevention research point to the importance of analysing and attempting to address the broader causes of suicidal ideation, rather than simply attempting to recognize such ideation and provide crisis support. We refer to this lens as the Situational Approach to Suicide Prevention, and Macdonald (2010) discusses how the build-up of these life stressors contribute to suicide among Australian men, for example, unemployment, relationship breakdown, social isolation, financial distress, history of intentional self-harm, drug and alcohol abuse and mental health difficulties. This article will explore one of these social determinants of suicide namely, the unemployment/underemployment.

\section{Background}

Employment is one of the major factors of individual wellbeing as it indicates and sometimes derives from the social status of an individual. As Smith (1985) puts it, "we define ourselves with our occupation". Employment or unemployment goes beyond the idea of income generation and plays a key role in organising an individual's life since it largely determines the educational opportunities, social contacts, and pension after the employment tenure. Once we see employment as one of the major social determinants of wellbeing of an individual, it will be easy to understand the link between unemployment/underemployment and reduced mental health. Suicide risk across different population groups changes during periods of economic crisis or uncertainty (Milner et al., 2019). For example, males appear to be more vulnerable than females to the negative impacts of economic downturn, which includes risk of suicide. Coope et al. (2014) reported that in the UK recession of 2008-09, suicide rates in England and Wales rose among men aged 35-44 and 45-64. This increase among men in their middle years may have been partly due to economic uncertainty, as suicides related to 
unemployment were nine times the number of deaths than the increase in suicides attributed to the most recent economic crisis. According to the NCIS report by Saar and Burgess (2016), over $55.05 \%$ of all suicide deaths were by people not employed for the years 2001-2013.

Further, Milner, Morrell and LaMontagne (2014) suggest that from 2001-2010, the suicide rate ratio (RR) of economically inactive/unemployed males was 4.62 [95\% confidence interval (CI) 4.10, 5.19; $\mathrm{P}<0.001]$ compared with employed males (RR1/41.00). Economically inactive/unemployed females had a suicide RR of 8.44 compared with employed females $(95 \%$ CI $7.38,9.67 ; p<0.001)$. These figures point to the need for adequate policy and welfare responses to ameliorate the impact of economic downturn on the workforce-aged population, especially in relation to unemployed and economically inactive people in Australia, who may carry a higher suicide risk than previously imagined. Indeed, Nordt, Warnke, Seifritz and Kawohl (2015) argue that prevention strategies focused on unemployment and its conditions are necessary not only in difficult times but also in times of stable economy. Additional research by Haw, Hawton, Gunnell and Platt (2020) proves substantial evidence of a link between recession, unemployment and suicide behaviour. Coope et al. (2014) further suggest that signs of economic strain other than unemployment or redundancy, for example personal debt and house repossessions, may contribute to increased suicide rates in younger males, while for men aged 35-44 years, job loss and long-term unemployment becomes a key risk factor. McDaid (2017) agrees with the majority of studies showing that unemployment is a risk factor for male suicide, and that this risk is exacerbated during an economic downturn. The correlation between female suicidal behaviour and unemployment is not as strong, although the risk may become more visible as growing numbers of women enter what were previously traditionally male-held employment roles and increasingly occupy more senior positions in the workforce. Other factors that may increase risk include a drop in relative income, unmanageable debt, the threat or fear or home repossessions, job insecurity and business downsizing. As a result, suicide prevention strategies that are multi-faceted should be carefully developed, focusing on minimisation of risk factors. For example, adequate social welfare payments, psychological support for unemployed people and those at risk of redundancy, training for employers and improved access to not-for-profit services offering debt advice (Macdonald et al., 2010). A recent report by Suicide Prevention Australia (2019) also emphasises the significance of focusing on life stressors in influencing suicidal behaviour alongside with mental illness. This report also mentions that unemployment and long periods of increased financial pressure can lead to severe consequences such as decrease in self-esteem and anxiety leading to suicidal behaviour.

\section{The Way Forward in Suicide Prevention}

\subsection{Existing Programs}

Over the past century, despite the research outlined above, psychiatric and psychological perspectives have dominated the ecological factors of mental health in 20th and 21st century (Macintyre et al., 2018). A review of evidence by Silva et al. (2016) found that there is a significant association between the sociodemographic characteristics of the individual and 
their mental health, highlighting the need to focus on social factors while addressing the mental health issues of any population. However, the current approach by both the funding agencies and the suicide prevention implementation organisations tend to be more focused on medical or crisis responses to individual mental health problems rather than understanding the contributing factors (Platt et al., 2017). According to Ashfield et al. (2017) there has been, in recent times, a substantial increase in the diagnosis of 'mental disorders'-depression and anxiety in particular - and a corresponding escalation of prescriptions for anti-depressant and anxiolytic medications. They argue that this correlation is largely a consequence of the limited scope in primary care settings for general practitioners to comprehensively respond to complex human experience and distress, possibly related to fewer appropriate referral options, and the requirement for Mental Health Treatment Plans. As McPhedran and De Leo (2013) state, it is very unlikely that there will be a reduction in the number of suicides if the prevention strategies only focus on access to mental health services and increased awareness of mental health services, ignoring the life experiences of individuals. This is because, as McPhedran and De Leo (2013) reported in their research, $40 \%$ of rural men had visited a mental health professional within 3 months before killing themselves. This suggests that the approach of those mental health professionals serving men needs to be changed, involving taking various socio-economic factors into consideration. In a report initiated by Lifeline Australia, Mendoza and Rosenberg (2010) also highlighted social factors such as loss of a loved one, breaking up of a significant relationship or losing a job as being the leading causes for suicides in Australia alongside emotional distress. Macintyre et al. (2018) state the significance of upstream interventions to include social determinants while challenging the current 'downstream' approach of suicide prevention, which only focuses on behavioural issues and biological risk factors. In a recent report by the United Nations Special Rapporteur on the right to Health, UN Human Rights (2020) has called for a shift in our approach to mental health, as the current approaches are dominated by gatekeepers of a biomedical model which allocate resources and guide principles for mental health policies and services, clearly backed by the pharmaceutical industry. He also warns that the current approach to mental health ignores socio-economic and cultural factors which can help to prevent suicides. Ashfield et al. (2017) also state that the funding to current suicide prevention strategies is often managed by local health bureaucracies or high-profile NGOs, which can be biased towards medicalising mental health and focusing on illness rather than whole spectrum of an individual's life events.

\subsection{Gender}

The consideration of gender points to a significant difference in responding to self-harm and suicide deaths. The majority of deaths are male but the majority of incidents of non-fatal self-harm are female. However, there is insufficient consideration of gender differences in suicide prevention or preventative mental health responses, other than the perpetuation of simplistic male stereotypes and the idea that 'men should be better at help-seeking' (Ashfield et al., 2017; Mendoza \& Rosenberg, 2010). For suicide prevention and intervention strategies to be more effective, they must be properly informed by the operation of gender differences. It is unfortunately and alarmingly conceivable that this oversight or simplification has 
contributed to an increase in suicide mortality in the last two decades, despite huge expenditure of public funds in this field.

\subsection{A Situational Approach to the Issue of Unemployment and Suicide}

The Situational Approach to suicide prevention acknowledges the predominant association of suicide with situational distress, as opposed to mental illness (although they can be linked in some cases). The approach is principally informed by risk factors of a broad spectrum of difficult human experiences across the life span and seeks to address contextual, systemic, and socio-cultural risk and protective factors - that is, the real world of an individual's lived experience - with appropriate, competent and gender specific responses to accumulated distress. This situational approach also involves seeking to address wider issues such as those, that are known to be implicated in people's distress. This contextual focus helps to avoid the individualisation of distress, whilst minimizing the potential for a 'blame-the victim' mentality that has sometimes been associated with solely individualistic problem-oriented clinical approaches. The vital importance of community engagement also needs to be emphasized for capacity building, primary prevention and early intervention initiatives. The proliferation of tertiary suicide response services aimed at working with people who have already attempted, have a high intensity mental health difficulty, or those bereaved by suicide (termed post-vention support (Macdonald et al., 2010)) pose a conundrum. Such services are definitely valuable, but a broader approach would contribute significantly more to reducing the suicide death toll. As mentioned above, recent international research provides a serious challenge to the general approach to suicide prevention, particularly as it applies to men. Current policy and practice are sometimes helpful to some men, but may actually compound the difficulties that some men face (Macdonald et al., 2010). Many studies, such as Reeves et al. (2014) and Milner et al. (2014), acknowledge that long periods of financial stress and unemployment are recognized factors in a large percentage of all suicides. These studies demonstrate that an increased risk can be associated with unemployment (especially more than six months), early retirement, and being classified as a 'homemaker', and these can be categorised independently of a psychiatric diagnosis. In addition, Schneider et al. (2011) contend that adverse working conditions, such as monotony, higher responsibility and emotional mental stress from client- contact have been shown to significantly increase suicide risk as well, again unrelated to a diagnosed mental illness. The situational approach would envisage that employment and more positive working conditions act as a preventative factor in suicide and poor mental health outcomes. This article has focused on unemployment as an example of a social determinant of suicide but gender, social gradient and Aboriginality are other significant contributing factors.

A case in point is The Shed in Mt Druitt, which operates as a drop-in centre for Aboriginal men in crisis. The Shed was established in 2004 as a partnership between the Men's Health Information and Resource Centre (MHIRC) at University of Western Sydney and the Holy Family Church at Mount Druitt (Macdonald \& Welsh, 2019). They showed that males in this region faced a similar set of issues common to many males in the Greater Western Sydney region. Both men and women can face difficulties brought on by unemployment, separation or loss, but the services facilitated by the Shed focus on the needs of men, thereby filling an 
important gap and providing the vital connections that men need to stay in life during times of trouble.

The Shed provides support to men (and now women) considered to be at risk of suicide, generally on account of cumulative stress from living in disadvantaged situations. Most of these men are of Aboriginal and Torres Strait Islander background, who statistically and realistically represent a population most at risk. The Commonwealth Department of Health and Ageing has funded the project since 2004 but is now funded by the local primary health network under the National Strategy for Prevention of Suicide. A fundamental tenet is that The Shed is a place where Aboriginal men talk to Aboriginal men (Jabour, 2017), but more broadly it partners with twenty-eight distinct support organisations who provide outreach to The Shed on a rotating basis. It has become an essential link between at-risk men and the services they could access but don't have opportunity to, know how to, or are not comfortable attempting to, contact. Panagiotaros et al. (2019) shared the stories of men like Charles, who said that The Shed helped him reconnect after a difficult period of being homeless. He went on to volunteer for the organisation and is now employed as a counselor. He said, "The Shed helped me straight away with support. It was a comfortable place to not be judged and to just be yourself. That's what I like about it!” (Panagiotaros et al., 2019, p. 8)

\section{Summary}

There are clear links between economic recession, unemployment and the risk of suicide. It is also reasonable to conclude that social determinants such as gender, Aboriginality and the social gradient need to be considered as additional risk factors. As a result, we recommend that:

- Program funding should be focused on developing a prevention strategy that caters for social determinants including unemployment and underemployment, acknowledging this as one of the major contributors to suicide.

- Examples of community-based suicide prevention programs be identified based on a situational approach (such as "The Shed" in Mt Druitt) and replicated across the country in order to reduce male suicides.

- As far as possible, governments, employers and support services ensure the allocation of resources within program budgets for re-training and redundancy.

These recommendations are drawn from an analysis of the links between unemployment and suicide and are informed by the situational approach to suicide prevention in a pre-COVID-19 situation. Considering the high unemployment rates and social isolation during and after the COVID-19, there is a greater need for policy makers to boost the funding for interventions focusing on the situational approach to reduce the suicide among men in Australia.

The authors declare no conflict of interest.

\section{References}

Ashfield, J., Macdonald, J. J., \& Smith, A. (2017). A 'Situational Approach'To Suicide 
Prevention. Web. 31 May 2017. https://doi.org/10.25155/2017/150417

Australian Bureau of Statistics (ABS). (2017). Causes of Deaths. Australia 2017, cat. no. 3303.0. April $\quad$ Retrieved 23, 2020, from https://www.abs.gov.au/ausstats/abs@.nsf/Lookup/by\%20Subject/3303.0 2017 Main\%20Fe atures $\sim$ About $\% 20$ this\%20Release 9999

Australian Bureau of Statistics. (2019). Causes of Deaths. Australia 2019, cat. no. 3303.0. Retrieved April 23, 2020, from https://www.abs.gov.au/ausstats/abs@.nsf/Lookup/by\%20Subject/3303.0 2018 Main\%20Fe atures $\sim$ Intentional $\% 20$ self-harm, $\% 20 \mathrm{key} \% 20$ characteristics $\sim 3$

Bastiampillai, T., Allison, S., Looi, J. C., Tavella, A., \& Agis, U. (2020). Why are Australia's suicide rates returning to the hundred-year average, despite suicide prevention initiatives? Reframing the problem from the perspective of Durkheim. Australian \& New Zealand Journal of Psychiatry, 54(1), 12-14. https://doi.org/10.1177/0004867419872815

Coope, C., Gunnell, D., Hollingworth, W., Hawton, K., Kapur, N., Fearn, V., ... Metcalfe, C. (2014). Suicide and the 2008 economic recession: who is most at risk? Trends in suicide rates in England and Wales 2001-2011. Social Science \& Medicine, 117, 76-85. https://doi.org/10.1016/j.socscimed.2014.07.024

Haw, C., Hawton, K., Gunnell, D., \& Platt, S. (2020). Economic recession and suicidal behaviour: Possible mechanisms and ameliorating factors. International Journal of Social Psychiatry, 61(1), 73-81. https://doi.org/10.1177/0020764014536545

Jabour, B. (2017). The Shed: I Keep coming because there are people who listen. Retrieved February 22, 2017, from https:/www.theguardian.com/australia-news/2017/feb/22/the-shed-i-keep-coming-because-th ere-are-people-who-listen

Macdonald, J. J. (2010). University of Western Sydney Men's Health Information \& Resource Centre. Pathways to despair: the social determinants of male suicide (pp. 25-44), Central Coast, NSW. Men's Health Information and Resource Centre, University of Western Sydney. Penrith South NSW.

Macdonald, J. J., \& Welsh, R. (2012). The Shed in Mt Druitt: Addressing the social determinants of male health and illness. Western Sydney University. Retrieved December 19, 2019 , from https://www.westernsydney.edu.au/_data/assets/pdf_file/0003/1308234/MHIC0437_TheShe dMtDruitt_FA_LR.pdf

Macintyre, A., Ferris, D., Gonçalves, B., \& Quinn, N. (2018). What has economics got to do with it? The impact of socioeconomic factors on mental health and the case for collective action. Palgrave Communications, 4(1), 1-5. https://doi.org/10.1057/s41599-018-0063-2

McDaid, D. (2017). Socioeconomic disadvantage and suicidal behaviour during times of economic recession and recovery. Dying from Inequality Summary Report; Samaritans 
Registered Office, Ewell UK.

McPhedran, S., \& De Leo, D. (2013). Miseries suffered, unvoiced, unknown? Communication of suicidal intent by men in "Rural" Queensland, Australia. Suicide and Life - Threatening Behavior, 43(6), 589-597. https://doi.org/10.1111/sltb.12041

Mendoza, J., \& Rosenberg, S. (2010). Suicide and suicide prevention in Australia: Breaking the silence. Lifeline Australia and Suicide Prevention Australia.

Milner, A., Aitken, Z., Law, P. C. F., LaMontagne, A. D., Mann, C., Cooper, T., \& Witt, K. (2019). The relationship between an electronic mental health stigma campaign and suicidal thoughts and behaviours: A two-arm randomized controlled trial in the Australian construction industry. Health Promotion International, 1-8. https://doi.org/10.1093/heapro/daz034

Milner, A., Morrell, S., \& LaMontagne, A. (2014). Economically inactive, unemployed and employed suicides in Australia by age and sex over a 10-year period: What was the impact of the 2007 economic recession? International Journal of Epidemiology, 43(5), 1500-1507. https://doi.org/10.1093/ije/dyu148

Morgan, C. (2019). A message from the national Suicide Prevention Advisor. The Department of Health. Retrieved December 19, 2019, from https://www1.health.gov.au/internet/main/publishing.nsf/Content/mental-national-suicide-pre vention-adviser

Nordt, C., Warnke, I., Seifritz, E., \& Kawohl, W. (2015). Modeling suicide and unemployment: A longitudinal analysis covering 63 countries, 2000-2011. The Lancet Psychiatry, 2(3), 239-245. https://doi.org/10.1016/S2215-0366(14)00118-7

OHCHR. (2020). World needs "revolution" in mental health care - UN rights expert [Internet]. Ohchrorg. Retrieved April 25, 2020, from https://www.ohchr.org/EN/NewsEvents/Pages/DisplayNews.aspx?NewsID=21689

Panagiotaros, C., Hall, N., \& Macdonald, J. J. (2019). In Our Words: Stories from The Shed Mt Druitt. Western Sydney University. Retrieved December 19, 2019, from http://www.mengage.org.au/images/The_Shed_Stories_1MB.pdf

Platt, S., Stace, S., \& Morrissey, J. (2017). Dying from inequality: Socioeconomic disadvantage and suicidal behaviour. Samaritans: London, UK.

Reeves, A., McKee, M., \& Stuckler, D. (2014). Economic suicides in the great recession in Europe and North America. The British Journal of Psychiatry, 205(3), 246-247. https://doi.org/10.1192/bjp.bp.114.144766

Ritchie, H., Roser, M., \& Ortiz-Ospina, E. (2020). Suicide. Published online at OurWorldInData.org. Retrieved March 12, 2020, from https://ourworldindata.org/suicide

Saar, E., \& Burgess, T. (2016). Intentional Self-Harm Fatalities in Australia 2001-2013. Data Report DR16-16. National Coronial Information System. 


\section{Macrothink}

Schneider, B., Grebner, K., Schnabel, A., Hampel, H., Georgi, K., \& Seidler, A. (2011). Impact of employment status and work-related factors on risk of completed suicide: A case-control psychological autopsy study. Psychiatry Research, 190(2-3), 265-270. https://doi.org/10.1016/j.psychres.2011.07.037

Silva, M., Loureiro, A., \& Cardoso, G. (2016). Social determinants of mental health: a review of the evidence. The European Journal of Psychiatry, 30(4), 259-292.

Smith, R. (1985). Occupationless health. I couldn't stand it anymore: Suicide and $\begin{array}{lllll}\text { unemployment. British } & \text { Medical Journal, }\end{array}$ https://doi.org/10.1136/bmj.291.6508.1563

Suicide Prevention Australia. (2019). Turning point: Imagine a world without suicide [Internet]. Retrieved from https://www.suicidepreventionaust.org/2019/09/10/turning-points-imagine-a-world-without-s uicide-2/

\section{Copyrights}

Copyright for this article is retained by the author(s), with first publication rights granted to the journal.

This is an open-access article distributed under the terms and conditions of the Creative Commons Attribution license (http://creativecommons.org/licenses/by/4.0/). 